\title{
OPTIMALISASI PRODUKSI MEUBEL PADA BALAI LATIHAN PENDIDIKAN TEKNIK (BLPT) KAATEN, KOTA TOMOHON
}

\author{
Ruth Elisa Simamora \\ Agnes E. Loho \\ Leonardus R. Rengkung
}

\begin{abstract}
This study aims to determine the optimization of products, resource use and sensitivity of production resources in furniture BLPT kaaten. The study was conducted from April 2017 to August 2017. The data used were primary and secondary data. Primary data is obtained from direct observation of company condition and interview with related parties of research in company while secondary data obtained from company include cost data, raw material, rescue material, human labor and machine worker. The method used in this reswarch is case study. The data analysis used is Linear Programming with the help of using software LINDO Version 6.1. The results show that BLPT Kaaten has been operating optimally producing 76 church benches within 100 days with RP profits. 77.615.470. The limiting resource in the production of KUDEN $B L P T$ furniture is the manpower of the finishing department. Resource sensitivity sensitive to the decrease of the availability of raw materials are brass hinges, sis locks, leaf size 3 and leaf knob size 3.5 .
\end{abstract}

Keywords: optimization of product, furniture production, Kaaten Sub-District, Tomohon City

\begin{abstract}
ABSTRAK
Penelitian ini bertujuan untuk mengetahui optimalisasi produk, penggunaan sumberdaya dan kepekaan sumberdaya produksi meubel pada BLPT kaaten. Penelitian dilaksanakan pada bulan April 2017 sampai Agustus 2017. Data yang digunakan adalah data primer dan sekunder. Data primer diperoleh dari pengamatan langsung terhdap kondisi perusahaan serta wawancara dengan pihak-pihak terkait penelitian di perusahaan sedangkan data sekunder diperoleh dari perusahaan meliputi data biaya, bahan baku, bahan penolong, tenaga kerja manusia dan tenaga kerja mesin. Metode yang digunakan dalam penelitian ini adalah studi kasus. Analisis data yang digunakan adalah Linier Programming dengan bantuan bantuan menggunakan software LINDO Versi 6.1. Hasil menunjukkan bahwa BLPT Kaaten telah beroperasi secara optimal yaitu memproduksi 76 unit bangku gereja dalam jangka waktu 100 hari dengan keuntungan RP. 77.615.470. Sumberdaya pembatas dalam kegiatan produksi meubel BLPT Kaaten adalah tenaga kerja manusia bagian finishing. Kepekaan sumberdaya peka terhdap penurunan ketersedian bahan baku yaitu engsel kuningan, kunci sis, kenop daun ukuran 3 dan kenop daun ukuran 3.5.
\end{abstract}

Kata kunci: optimalisasi produk, produksi meubel, Kelurahan Kaaten, Kota Tomohon 


\section{PENDAHULUAN}

\section{Latar Belakang}

Industri adalah seluruh bentuk kegiatan ekonomi yang mengolah bahan baku dan/atau memanfaatkan sumber daya industri sehingga menghasilkan barang yang mempunyai nilai tambah atau manfaat lebih tinggi, termasuk jasa industri (Undang-Undang Nomor 3 Tahun 2015 tentang Perindustrian). Secara umum pengertian industri adalah bagian dari suatu proses yang mengelola bahan mentah menjadi bahan baku atau bahan baku menjadi barang jadi, sehingga menjadi suatu barang yang memiliki nilai bagi masyarakat (Hinsa Sahaan). Di Indonesia, pengelompokan industri dapat digolongkan kedalam beberapa macam yang didasarkan pada banyaknya tenaga kerja meliputi: industri besar, industri sedang, industri kecil dan industri rumah tangga (BPS, 2002).

Industri meubel merupakan salah satu komoditi penghasil devisa negara sesudah minyak dan gas, sebagai home industri yang memiliki nilai seni yang cukup tinggi, sehingga industri meubel di negara Indonesia mampu memenuhi kebutuhan masyarakat mancanegara. Industri meubel juga merupakan salah satu agenda pembangunan Indonesia dalam rangka meningkatkan kesejahteraan rakyat. (Wulandy, 2011 dalam Fachmi).

Para pengusaha industri meubel melakukan pekerjaan dengan tujuan untuk memperoleh pendapatan demi kebutuhan hidup. Untuk pelaksanaannya diperlukan beberapa perlengkapan dan dipengaruhi oleh banyak faktor guna mendukung keberhasilan kegiatan. Faktor yang mempengaruhi pendapatan dan produksi industri meubel meliputi sektor sosial dan ekonomi yang terdiri dari besarnya modal, jumlah tenaga kerja, pengalaman kerja, dan teknologi (Salim, 1999).

Pendapatan dan produksi industri meubel berdasarkan besar kecilnya kemampuan produksi. Semakin besar modal usaha semakin besar pula kemampuan industri meubel memproduksi meubel, akan tetapi sekalipun industri meubel ini didukung dengan modal usaha yang besar akan tetapi tidak didukung dengan tenaga kerja yang berpengalaman maka produksi industri meubel tidak akan pernah mendapatkan hasil yang memuaskan.
Dunia industri, perbandingan antara biaya produksi dengan harga jual sangat mempengaruhi daya saing di pasar. Biaya produksi sangat ditentukan oleh efisiensi dan perhitungan perbandingan input terhadap output dalam proses produksi. Efisiensi merupakan tindakan memaksimalkan hasil dengan modal (tenaga kerja, material dan alat) yang minimal. Efisiensi juga dapat diartikan sebagai upaya penggunaan input yang sekecil-kecilnya untuk mendapatkan produksi sebesar-besarnya. Dengan demikian, pihak manjemen dapat mengkombinasikan faktorfaktor produksi dengan teknik pengelolaan tertentu sehingga dapat menghasilkan suatu produk secara efektif dan efisien dalam jumlah, kualitas, waktu maupun biaya produksinya.

BLPT Kaaten yang berlokasi di Tomohon, merupakan sebuah industri meubel yang berbahan baku kelapa dan yang bergerak dalam bidang produksi dan pemasaran yaitu souvenir, meubel, perlengkapan gereja dan bangunan. Seluruh produk BLPT yang diproduksi sesuai dengan permintaan konsumen. Adapun produk yang paling sering dipesan adalah bangku gereja, sampiran bangku gereja, kotak persembahan, dan bangku $\mathrm{HK}$.

\section{Rumusan Masalah}

1. Apakah BLPT Kaaten sudah beroperasi secara optimal?

2. Sumber daya apa yang menjadi pembatas dalam kegiatan produksi meubel pada BLPT Kaaten?

3. Bagaimana kepekaan sumberdaya pada proses produksi di BLPT Kaaten?

\section{Tujuan Penelitian}

1. Untuk mengetahui bahwa BLPT Kaaten sudah beroperasi secara optimal.

2. Untuk mengetahui sumberdaya yang menjadi pembatas dalam kegiatan produksi meubel pada BLPT Kaaten.

3. Untuk mengetahui kepekaan sumberdaya pada proses produksi di BLPT Kaaten. 


\section{Manfaat Penelitian}

1. Penelitian ini diharapkan dapat memberikan masukan dan sumber pemikiran yang baru bagi perusahaan.

2. Penelitian ini diharapkan dapat memberikan manfaat berupa pengetahuan dan dapat menjadi saran untuk mengaplikasikan ilmu yang diperoleh.

3. Penelitian ini diharapkan dapat dijadikan bahan referensi bagi penelitian selanjutnya.

\section{METODOLOGI PENELITIAN}

\section{Waktu dan Tempat Penelitian}

Penelitian ini dilakukan pada bulan April 2017 sampai Agustus 2017. Tempat penelitian berada di BLPT Kaaten yang beralamat di Kaaten Kota Tomohon.

\section{Pengumpulan Data}

Data yang digunakan dalam penelitian ini adalah data primer dan data sekunder. Data primer diperoleh dari pengamatan secara langsung terhadap kondisi perusahaan serta wawancara dengan pihak-pihak terkait penelitian di perusahaan. Data sekunder diperoleh dari perusahaan meliputi data bahan baku, bahan penolong, tenaga kerja, jam mesin dan biaya.

Metode pengumpulan data yang dilakukan pada penelitian ini terdiri dari:

1. Wawancara

Wawancara dilakukan untuk melengkapi informasi yang diperoleh dan wawancara ini menyangkut 5 bagian yaitu bagian persiapan, mesin, perakitan, finishing dan kantor.

2. Observasi

Observasi dilakukan dengan melakukan proses pengamatan langsung terhadap kondisi yang ada di perusahaan. Proses identifikasi dilakukan untuk mengetahui mekanisme pengendalian persediaan dan aktivitas-aktivitas terkait.

3. Metode Penelitian

Metode yang digunakan dalam penelitian ini adalah studi kasus.

\section{Konsepsi Pengukuran Variabel}

Untuk merumuskan variabel model optimasi maka variabel yang di ukur meliputi:

1. Variabel Fungsi Tujuan:

$$
\mathrm{Z}: \mathrm{CX}_{1}+\mathrm{CX}_{2}+\mathrm{CX}_{3}+\mathrm{CX}_{4}
$$

Dimana:

$\mathrm{X} 1$ : Kotak persembahan

$\mathrm{X} 2$ : Kursi HK

X3 : Bangku gereja

$\mathrm{X} 4$ : Sampiran gereja

2. Variabel Fungsi Kendala meliputi: Penggunaan bahan Baku: Kayu kelapa $\left(\mathrm{m}^{3}\right)$, Lem fox $(\mathrm{kg})$, Engsel kuningan (biji), Sekrup 2 inci, $1 \frac{1}{2} 2$ inci, 1 inci, $1 \frac{1}{1} 4$ inci (biji), Kenop daun uk 3,2 dan uk 4 (biji), Kunci Sis (biji), Kertas pasir uk 120 dan uk 400 (lembar), Tinner N.D (liter), Wood Filler (liter), Melamin seanding sealer (liter), Melamin clear gloss (liter).

1. Penggunaan bahan Baku: Kayu kelapa $\left(\mathrm{m}^{3}\right)$, Lem fox $(\mathrm{kg})$, Engsel kuningan (biji), Sekrup 2 inci, 1 1/2 inci, 1 inci, 1 11/4 inci (biji), Kenop daun uk 3,2 dan uk 4 (biji), Kunci Sis (biji), Kertas pasir uk 120 dan uk 400 (lembar), Tinner N.D (liter), Wood Filler (liter), Melamin seanding sealer (liter), Melamin clear gloss (liter).

2. Penggunaan Tenaga Kerja Manusia: Persiapan ( menit), Mesin/ pengasahan (menit), Perakitan (menit), Finishing (menit).

3. Penggunaan Tenaga Kerja Mesin (Jam kerja mesin): Mesin penebal (menit), Mesin perata (menit), Mesin bubut (menit), Mesin frais (menit), Mesin iris (menit), Mesin potong (menit), Mesin kompressor (menit), Mesin amplas besar (menit), Mesin amplas kecil (menit), Mesin pembuat lidah/pen (menit), Mesin routter (menit), Mesin Bor vertikal (menit), Mesin Bor horizontal (menit).

3. Variabel Right Hand Side (RHS) meliputi:

1. Ketersediaan bahan Baku: Kayu kelapa $\left(\mathrm{m}^{3}\right)$, Lem fox (kg), Engsel kuningan (biji), Sekrup 2 inci, 1 1/2 inci, 1 inci, 1 1/4 inci (biji), Kenop daun uk 3,2 dan uk 4 (biji), Kunci Sis (biji), Kertas pasir uk 120 dan uk 400 (lembar), Tinner N.D (liter), Wood Filler (liter), Melamin seanding sealer (liter), Melamin clear gloss (liter). 
2. Ketersediaan Tenaga Kerja Manusia : Persiapan ( menit), Mesin/ pengasahan (menit), Perakitan (menit), Finishing (menit).

3. Ketersediaan Tenaga Kerja Mesin (Jam kerja mesin): Mesin penebal (menit), Mesin perata (menit), Mesin bubut (menit), Mesin frais (menit), Mesin iris (menit), Mesin potong (menit), Mesin kompressor (menit), Mesin amplas besar (menit), Mesin amplas kecil (menit), Mesin pembuat lidah/pen (menit), Mesin routter (menit), Mesin Bor vertikal (menit), Mesin Bor horizontal (menit).

\section{Analisis Data}

Analisis data yang digunakan Linier Programming dan data diolah menggunakan software LINDO versi 6.1 yang diciptakan oleh Professsor Linus Scrage dari Graduate School of Business, Chicago. Dengan menggunakan model linier programming sebagai berikut:

1) Fungsi Tujuan

$$
\begin{aligned}
\text { Z: CX } & \\
\text { Fungsi Kendala. } & \leq \\
\text { Kendala 1: } \mathrm{a}_{11} \mathrm{X}_{1}+\mathrm{a}_{12} \mathrm{X}_{2}+. .+\mathrm{a}_{1 \mathrm{n}} \mathrm{X}_{\mathrm{n}} & =\mathrm{b}_{1} \\
& \geq \\
\text { Kendala 2: } \mathrm{a}_{21} \mathrm{X}_{1}+\mathrm{a}_{22} \mathrm{X}_{2}+. .+\mathrm{a}_{2 \mathrm{n}} \mathrm{X}_{\mathrm{n}} & =\mathrm{b}_{2} \\
& \geq \\
& \leq \\
\text { Kendala } \mathrm{n}: \mathrm{a}_{\mathrm{i} 1} \mathrm{X}_{1}+\mathrm{a}_{\mathrm{i} 2} \mathrm{X}_{2}+\ldots+\mathrm{a}_{\mathrm{mn}} \mathrm{X}_{\mathrm{n}} & =\mathrm{b}_{\mathrm{i}} \\
& \geq \\
\mathrm{X}_{\mathrm{j}} & \geq 0
\end{aligned}
$$

\section{HASIL DAN PEMBAHASAN}

\section{Gambaran Umum Perusahaan}

BLPT Kaaten merupakan salah satu produsen meubel di Sulawesi Utara khususnya di sekitar kota Tomohon. Usaha ini didirikan langsung oleh GMIM pada tahun 1987. Pada awalnya usaha ini merupakan usaha uji coba yang diberikan dengan nama BKLK. Kemudiaan usaha ini mengalami perkembangan hingga seiring berjalannya waktu pada tahun 1992 usaha meubel ini pun mengganti nama menjadi BLPT Kaaten. Untuk mendukung pemasaran produk dari BLPT Kaaten ini, khususnya dalam menyakinkan pembeli bahwa produk yang dijualnya tersebut aman, berkualitas, tahan lama dan menarik, maka pihak BLPT Kaaten menggunakan bahan baku yang berkualitas juga.

Jenis meubel yang diproduksi oleh BLPT kaaten sangatlah beragam baik dalam segi bentuk, ukuran dan kualitas. Selain jenis meubel pihak BLPT Kaaten juga memproduksi berbagai jenis souvenir dan bahan bangunan. Disamping jenis meubel yang diproduksi oleh BLPT Kaaten semakin beragam, maka saat ini BLPT Kaaten juga sudah ada beberapa pelanggan yang dari dalam dan Luar negeri yang memesan produk meubel dari BLPT Kaaten.

BLPT Kaaten saat ini banyak memproduksi produk yang sesuai permintaan dari konsumen yang diantaranya adalah kotak persembahan, kursi HK, bangku gereja dan Sampiran gereja. Dalam proses produksi meubel ini juga menggunakan beberapa mesin dalam menghasilkan produk yang diinginkan serta beberapa karyawan yang telah ditetapkan dalam setiap bagiannya.

\section{Struktur Organisasi}

Berdasarkan hasil observasi di lapangan BLPT Kaaten memiliki struktur organisasi secara tertulis. Gambaran umum mengenai struktrur Organisasi BLPT Kaaten dapat dilihat pada gambar 1 berikut ini:

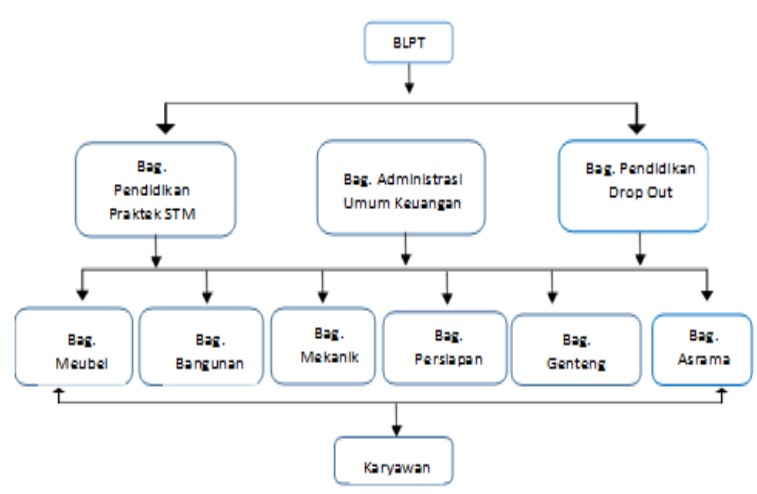

Gambar 1. Struktur Organisasi BLPT Kaaten, Tomohon (2016)

Gambar 1. Menunjukkan bahwa struktur organisasi BLPT Kaaten termasuk tipe organisasi fungsional, dimana pihak BLPT Kaaten telah melakukan pembagian tugas dalam operasionalnya. Untuk lebih jelasnya dapat diuraikan sebagai berikut: 
a. Bagian pendidikan Praktek STM adalah sekolah non formal yang disediakan BLPT untuk siswa-siswa sekolah kejuruan yang akan melakukan praktek dan magang. Bagian pendidikan praktek STM meliputi 1 orang bagian pendidikan dan 1 orang bagian barang kecil/souvenir.

b. Bagian Administrasi umum dan keuangan terdiri dari 1 orang kepala, 1 orang bag. Produksi, 1 orang bag. Marketing, 1 orang bag. Personalia, 1 orang bag. Operasional, dan 1 orang bag. Adm keuangan yang memiliki tugas berdasarkan jabatan masing-masing.

c. Bagian pendidikan Drop Out Kursus meliputi bagian asrama. Dimana bagian drop out kursus adalah sekolah luar biasa untuk anakanak penyandang cacat.

d. Bagian meubel bertugas untuk membuat produk meubel yang dipesan.

e. Bagian Bangunan bertugas untuk membuat bahan bangunan yang dipesan.

f. Bagian mekanik bertugas untuk memperbaiki mesin mesin yang rusak di BLPT itu sendiri.

g. Bagian persiapan bertugas untuk menyediakan kayu kelapa yang dibentuk sesuai ukuran yang ada.

h. Bagian genteng bertugas untuk membuat genteng bangunan yang dibutuhkan.

i. Bagian asrama bertugas menyediakan asrama untuk siswa yang sedang belajar atau melaksanakan magang di BLPT.

j. Karyawan bertugas untuk melaksanakan seluruh pekerjaan yang telah ditetapkan di masing masing bagian.

\section{Proses Produksi}

Proses produksi dalam pembuatan meubel dari BLPT Kaaten memiliki beberapa peralatan yang digunakan dalam proses pembuatan meubel yaitu mesin potong, mesin perata, mesin iris, mesin penebal, mesin pen, mesin frais, mesin bubut, mesin amplas kecil dan besar, mesin kompressor, mesin bor vertikal dan horizontal. Untuk menjaga loyalitas pelanggannya, pihak BLPT Kaaten sangat mengutamakan kulitas produk dan melakukan sortasi terhadap bahan baku yang akan dipakai untuk menghasilkan produk yang diproduksinya sehinga pelangan benar-benar memperoleh produk yang berkualitas. Berikut ini akan diperlihatkan proses produksi pembuatan meubel pada BLPT Kaaten, yaitu:

a) Persiapan Bahan Baku

Di dalam proses persiapan ini dilakukan pengeringan kayu kelapa, pemotongan kayu kelapa dan penempelan kayu kelapa sesuai dengan desain produk yang dipesankan. Di bagian persiapan ini digunakan beberapa mesin untuk melakukan prosesnya yaitu: oven, mesin potong, mesin perata, mesin iris dan mesin penebal. Untuk tenaga kerja manusia pada bagian persiapan ini diperlukan sebanyak 1 karyawan.

b) Mesin/Pengasahan

Dibagian ini setiap potongan kayu kelapa dirapikan dan dilubangi sesuai dengan konstruksi yang ditentukan sebelum masuk dibagian perakitan. Di bagian mesin/ pengasahan ini digunakan beberapa mesin untuk melakukan prosesnya yaitu: mesin potong, mesin bor horizontal dan vertikal, mesin iris, mesin pen, mesin frais, mesin bubut, mesin amplas besar dan mesin amplas kecil. Untuk tenaga kerja manusia pada bagian mesin/pengasahan ini diperlukan sebanyak 2 karyawan.

c) Perakitan

Dibagian ini semua kayu yang sudah di bentuk sesuai pola akan dirakit sesuai model yang diinginkan oleh konsumen. Di bagian perakitan ini digunakan 2 jenis mesin untuk melakukan prosesnya yaitu: mesin bor dan mesin Routter. Untuk tenaga kerja manusia pada bagian perakitan ini diperlukan sebanyak 2 karyawan.

d) Finishing

Finishing merupakan proses terakhir dalam produksi meubel. Dibagian ini setiap produk yang telah dibuat akan di rapikan kemudian dicat. Untuk bagian finishing ini dugunakan mesin kompressor untuk proses penyelesaianya. Untuk tenaga kerja manusia pada bagian finishing ini diperlukan sebanyak 1 karyawan. 


\section{Perumusan Model Linier Programming}

Perumusan model Linier Programming terdiri dari perumusan variabel keputusan, perumusan fungsi tujuan, dan perumusan fungsi kendala. Adapun kendala yang menjadi pembatas dalam kegiatan produksi meubel BLPT Kaaten adalah kendala bahan baku utama, jam tenaga kerja langsung, jam kerja mesin, dan permintaan.

\section{Perumusan variabel keputusan}

Jenis meubel yang dihasilkan oleh BLPT Kaaten adalah meja, kursi, lemari, tempat tidur, sampiran gereja,bangku gereja dan jenis lainnya dengan berbagai macam bentuk dan ukuran yang berbeda. Kuantitas produksi per tahun untuk meubel yang sering laku merupakan variabel keputusan dari model Linier Programming sehingga dalam penyusunan model dapat terbentuk 4 variabel keputusan yaitu:

$\mathrm{X} 1$ = Produksi Kotak Persembahan (unit)

X2 = Produksi kursi HK (unit)

X3 = Produksi bangku gereja (unit)

X4 = Produksi Sampiran gereja (unit)

\section{Perumusan Fungsi Tujuan}

Fungsi tujuan yang dirumuskan dalam penelitian ini bertujuan untuk mengetahui keuntungan kotor maksimal dari produksi meubel di BLPT Kaaten. Untuk mencapai tujuan tersebut, perusahaan harus memiliki perencanaan produksi yang baik. Adapun keuntungan terbesar yang dapat dilihat dari Tabel 1 adalah produk Bangku gereja dibandingkan dengan ketiga produk lainnya.

Tabel 1. Harga Jual Per Unit, Biaya Total Per Unit, Dan Keuntungan Per Unit Produk Meubel Pada BLPT Kaaten

\begin{tabular}{llrrr}
\hline Variabel & Jenis meubel & $\begin{array}{r}\text { Harga jual } \\
\text { per unit (RP) }\end{array}$ & $\begin{array}{r}\text { Biaya total } \\
\text { per unit (Rp) }\end{array}$ & $\begin{array}{r}\text { Keuntungan } \\
\text { per unit (Rp) }\end{array}$ \\
\hline X1 & Kotak persembahan & 2.000 .000 & 1.843 .202 & 156.798 \\
X2 & Kursi HK & 1.950 .000 & 1.861 .875 & 88.125 \\
X3 & Bangku gereja & 3.800 .000 & 2.781 .297 & 1.018 .703 \\
X4 & Sampiran gereja & 3.600 .000 & 2.859 .620 & 740.380 \\
\hline \multicolumn{2}{l}{ Sumber: BLPT Kaaten Tahun 2016 } & &
\end{tabular}

Kombinasi produksi yang optimal dari empat jenis meubel berdasarkan keuntungan per unit meubel dapat diketahui dengan merumuskan model fungsi tujuannya. Berdasarkan Tabel 1. Maka dapat dilihat model perumusan Linier Programming sebagai berikut:

Max: $156798 \times 1+88125$ x2 + 1018703 x $3+740380 \times 4$.

\section{Perumusan Fungsi kendala bahan baku}

BLPT Kaaten menggunakan bahan baku untuk memproduksi meubel berdasarkan standar pemakaian yang telah ditetapkan. Penggunaan bahan baku yang sesuai standar pemakaiannya merupakan nilai koefisien dari fungsi kendala bahan baku. Ketersediaan bahan baku merupakan nilai ruas kanan dan fungsi kendala bahan baku.

Berdasarkan Tabel 2 dapat dilihat data penggunaan bahan baku utama dan model perumusan Linier Programming fungsi kendala bahan baku.

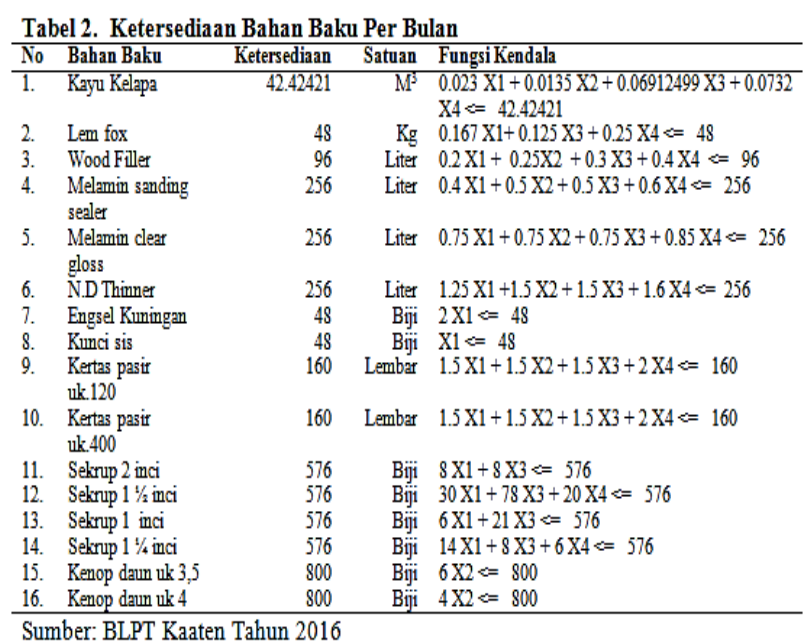

\section{Perumusan Fungsi Kendala Jam Tenaga Kerja Manusia}

Tenaga kerja yang digunakan dalam fungsi kendala jam tenaga kerja bagian produksi adalah tenaga kerja yang berkaitan langsung dengan proses produksi meubel pada BLPT Kaaten. Jumlah tenaga kerja bagian produksi pada BLPT Kaaten adalah 27 orang yang bekerja selama 8 jam per hari. Kebutuhan jam tenaga kerja bagian produksi untuk menghasilkan satu unit meubel dapat dirumuskan dalam fungsi kendala jam tenaga kerja bagian produksi dari model Linier Programming sebagai berikut:

Bagian Persiapan: $220 \mathrm{X} 1+180$ X2 $+290 \mathrm{X} 3+270 \mathrm{X} 4<=480$ Bagian Mesin $\quad: 175 \mathrm{X} 1+260 \mathrm{X} 2+315 \mathrm{X} 3+255 \mathrm{X} 4<=960$ Bagian Perakitan: $660 \mathrm{X} 1+600 \mathrm{X} 2+780 \mathrm{X} 3+900 \mathrm{X} 4<=960$ Bagian Finishing: 465 X1+495 X2+630 X3+675 X4 $<=480$

Dilihat dari kebutuhan tenaga kerja dalam keempat produk ini, yang memiliki waktu terlama dalam proses produksinya adalah pembuatan sampiran bangku gereja sebesar 2.100 menit per satu kali produksi. 


\section{Perumusan fungsi kendala Jam Tenaga Kerja Mesin}

Jam kerja mesin untuk menghasilkan satu unit meubel diperoleh dari total jam kerja mesin yang dibutuhkan dalam satu kali produksi. Ketersediaan jam kerja mesin merupakan nilai ruas kanan, sedangkan koefisien fungsi kendala jam kerja mesin adalah jam kerja mesin yang dibutuhkan untuk memperoleh satu unit meubel untuk setiap jenisnya. Dalam proses produksi meubel ini memiliki beberapa mesin yang digunakan dalam setiap bagian dalam proses produksi, meliputi:

1. Bagian Persiapan

BLPT Kaaten menggunakan 4 jenis mesin dalam bagian persiapan. Dimana untuk jam kerja keempat mesin ini adalah 8 jam per mesin dalam 1 hari. Sehingga Adapun fungsi kendala jam kerja mesin bagian persiapan dari model linear programming dapat dirumuskan sebagai berikut:

Mesin potong : $15 \mathrm{X} 1+20 \mathrm{X} 2+35 \mathrm{X} 3+30 \mathrm{X} 4<=480$ Mesin perata : $20 \mathrm{X} 1+25 \mathrm{X} 2+45 \mathrm{X} 3+35 \mathrm{X} 4<=480$ Mesin iris $: 15 \times 1+20 \times 2+20 \times 3+30 X 4<=480$ Mesin penebal : $20 \mathrm{X} 1+15 \mathrm{X} 2+25 \mathrm{X} 3+25 \mathrm{X} 4<=480$

Dilihat dari kebutuhan tenaga kerja mesin dalam bagian persiapan ini, yang memiliki waktu terlama dalam proses produksinya adalah pembuatan bangku gereja sebesar 125 menit per satu kali produksi. Keempat mesin diatas memiliki perbedaan dalam proses produksinya. Mesin potong berfungsi untuk membuat bentuk dasar dari meubel tersebut dan membelah kayu berbentuk persegi panjang sesuai ukuran yang telah ditetapkan, mesin iris berfungsi untuk mengiris balok kayu sesuai dengan bentuk dan ukuran yang diinginkan, mesin perata berfungsi untuk meratakan permukaan balok kayu, dan mesin penebal berfungsi untuk mengatur ketebalan dari balok kayu yang ada.

2. Bagian Mesin

BLPT Kaaten menggunakan 9 jenis mesin dalam bagian persiapan. Dimana untuk jam kerja kesembilan mesin ini adalah 8 jam per mesin dalam 1 hari. Adapun fungsi kendala jam kerja mesin bagian persiapan dari model linear programming dapat dirumuskan sebagai berikut:

\begin{abstract}
Mesin Potong : $15 \mathrm{X} 1+20 \mathrm{X} 2+30 \mathrm{X} 3+30 \mathrm{X} 4<=480$
Mesin iris $\quad: 5 \mathrm{X} 1+10 \mathrm{X} 2+5 \mathrm{X} 3+5 \mathrm{X} 4<=480$

Mesin bor vertikal: $10 \mathrm{X} 1+10 \mathrm{X} 2+40 \mathrm{X} 3+5 \mathrm{X} 4<=480$

Mesin bor horizontal: $15 \mathrm{X} 1+40 \mathrm{X} 2+20 \mathrm{X} 3+20 \mathrm{X} 4<=480$

Mesin pembuat lidah/pen: $5 \mathrm{X} 1+25 \mathrm{X} 2+5 \mathrm{X} 3+20 \mathrm{X} 4<=480$

Mesin frais $\quad: 10 X 1+10 X 2+5 X 3+20 X 4<=480$

Mesin amplas besar: $15 \mathrm{X} 1+30 \mathrm{X} 2+70 \mathrm{X} 3+40 \mathrm{X} 4<=480$

Mesin amplas kecil: $5 \mathrm{X} 1+15 \mathrm{X} 2+5 \mathrm{X} 3+10 \mathrm{X} 4<=480$

Mesin bubut $\quad: 10 \times 1<=480$
\end{abstract}

Dilihat dari kebutuhan tenaga kerja mesin dalam bagian mesin/persiapan ini, yang memiliki waktu terlama dalam proses produksinya adalah pembuatan bangku gereja sebesar 180 menit per satu kali produksi. Kesembilan mesin diatas memiliki perbedaan dalam proses produksinya. Mesin potong berfungsi untuk membuat bentuk dasar dari meubel tersebut dan membelah kayu berbentuk persegi panjang sesuai ukuran yang telah ditetapkan, mesin iris berfungsi untuk mengiris balok kayu sesuai dengan bentuk dan ukuran yang diinginkan, mesin bor berfungsi untuk membuat lubang sekrup pada balok kayu, mesin pen berfungsi untuk membuat pen dalam balok kayu, mesin amplas berfungsi untuk menghaluskan balok yang telah dibentuk agar menghasilkan kayu tanpa serat sama sekali pada permukaannya, dan terakhir mesin bubut berfungsi untuk membuat pola bentuk bulat seperti cekungan.

3. Bagian Perakitan

BLPT Kaaten menggunakan 2 jenis mesin dalam bagian persiapan. Dimana untuk jam kerja kedua mesin ini adalah 8 jam per mesin dalam 1 hari.Adapun fungsi kendala jam kerja mesin bagian persiapan dari model linear programming dapat dirumuskan sebagai berikut:

Mesin bor: $300 \times 1+180 \times 2+300 \times 3+360 \times 4<=480$ Mesin Routter : $240 \mathrm{X} 1+300 \mathrm{X} 2+360 \mathrm{X} 3+420 \mathrm{X} 4<=480$

Dilihat dari kebutuhan tenaga kerja mesin dalam bagian perakitan ini, yang memiliki waktu terlama dalam proses produksinya adalah pembuatan sampiran bangku gereja sebesar 180 menit per satu kali produksi. Kedua mesin diatas memiliki perbedaan dalam proses produksinya. Mesin bor berfungsi untuk membuat lubang sekrup pada balok kayu dan mesin Rouuter berfungsi untuk membentuk alur dan ulir pada kayu. 


\section{Bagian Finishing}

BLPT Kaaten menggunakan 1 jenis mesin dalam bagian persiapan. Dimana untuk jam kerja mesin ini adalah 8 jam per mesin dalam 1 hari. Adapun fungsi kendala jam kerja mesin bagian persiapan dari model linear programming dapat dirumuskan sebagai berikut:

Mesin Kompressor:

$60 \times 1+75 \times 2+105 \times 3+120 \times 4<=480$

Dilihat dari kebutuhan tenaga kerja mesin dalam bagian perakitan ini, yang memiliki waktu terlama dalam proses produksinya adalah pembuatan sampiran bangku gereja sebesar 120 menit per satu kali produksi. Untuk mesin kompressor ini berfungsi untuk meningkatkan tekanan atau memapatkan fluida gas atau udara.

\section{Perumusan Fungsi Kendala Permintaan}

Untuk mempertahankan pangsa pasarnya maka BLPT kaaten harus memenuhi permintaan dari konsumen darai masing masing produk yang dihasilkan. Dalam penelitian ini kendala permintaan minimum adalah jumlah penjualan masing masig produk meubel dalam setahun produksi. Jumlah penjualan meubel di BLPT Kaaten dapat dilihat pada Tabel 3.

Tabel 3. Penjualan Meubel Pada BLPT Kaaten.

\begin{tabular}{llr}
\hline Variabel & Jenis meubel & Penjulan (unit) \\
\hline X1 & Kotakpersembahan & 18 \\
X2 & Kursi HK & 8 \\
X3 & Bangku gereja & 31 \\
X4 & Sampiran bangku gereja & 8 \\
\hline
\end{tabular}

Sumber: BLPT Kaaten Tahun 2016

Maka fungsi kendala permintaan minimum dapat dirimuskan sebagai berikut:

$\mathrm{X} 1=18$

$\mathrm{X} 2=8$

$\mathrm{X} 3=31$

$\mathrm{X} 4=8$

\section{Tingkat Produksi Optimal}

BLPT Kaaten dalam melakukan kegiatan produksi meubel akan selalu dibatasi oleh berbagai kendala. Kendala tersebut adalah bahan baku, jam tenaga kerja manusia, jam tenaga kerja mesin, dan permintaan. Olahan data dengan menggunakan LINDO memperlihatkan hasil luaran model optimalisasi produksi yang diperoleh BLPT Kaaten. Hasil olahan model optimalisasi menunjukkan bahwa BLPT kaaten berproduksi secara optimal dengan asumsi bahwa dalam 100 hari harus memproduksi bangku gereja sebanyak 76 unit bangku dengan tingkat keuntungan sebesar Rp.776.154 dibandingkan dengan produksi aktual sebanyak 31 unit Bangku gereja.

\section{Hasil Optimasi Penggunaan Sumberdaya}

Sumber daya merupakan salah satu faktor yang dapat mempengaruhi produksi meubel pada setiap kali berproduksi. Tingkat produksi meubel sangat dipengaruhi oleh ketersediaan sumber daya yang ada dan disesuaikan dengan permintaan yang ada, maka perusahaan harus dapat memanfaatkan sumber daya yang ada untuk mencapai tingkat produksi optimal. Hasil dari optimasi terdapat analisis dual. Adapun rinciannya sebagai berikut:

1. Penggunaan Bahan Baku

Penggunaan bahan baku selama satu periode produksi setelah dilakukan optimasi dapat dilihat dalam Tabel 4.

Tabel 4. Hasil Optimasi Penggunaan Bahan Baku

\begin{tabular}{|c|c|c|c|}
\hline Bahan Baku & Slack/Surplus & $\begin{array}{r}\text { Dual } \\
\text { Prices }\end{array}$ & Status \\
\hline Kayu Kelapa & 42.371540 & 0.000000 & Berlebih \\
\hline Lem Fox & 47.904762 & 0.000000 & Berlebih \\
\hline Wood Filler & 95.771431 & 0.000000 & Berlebih \\
\hline Thinner N.D & 254.857147 & 0.000000 & Berlebih \\
\hline Melamin & 255.619049 & 0.000000 & Berlebih \\
\hline Sanding sealer & & & \\
\hline $\begin{array}{l}\text { Melamine clear } \\
\text { gloss }\end{array}$ & 255.428574 & 0.000000 & Berlebih \\
\hline $\begin{array}{l}\text { Kertas pasir } \\
\text { uk. } 120\end{array}$ & 158.857147 & 0.000000 & Berlebih \\
\hline $\begin{array}{l}\text { Kertas pasir uk. } \\
400\end{array}$ & 158.857147 & 0.000000 & Berlebih \\
\hline $\begin{array}{l}\text { Engsel } \\
\text { kuningan }\end{array}$ & 48.000000 & 0.000000 & Berlebih \\
\hline Kunci sis & 48.000000 & 0.000000 & Berlebih \\
\hline Sekrup 2 inci & 569.904785 & 0.000000 & Berlebih \\
\hline Sekrup 1,5 inci & 516.571411 & 0.000000 & Berlebih \\
\hline Sekrup 1 inci & 560.000000 & 0.000000 & Berlebih \\
\hline Sekrup 0,75 inci & 569.904785 & 0.000000 & Berlebih \\
\hline $\begin{array}{l}\text { Kenop Daun } \\
\text { Uk. } 3,5\end{array}$ & 800.000000 & 0.000000 & Berlebih \\
\hline $\begin{array}{l}\text { Kenop Daun } \\
\text { uk } 4\end{array}$ & 800.000000 & 0.000000 & Berlebih \\
\hline
\end{tabular}

Hasil optimasi ini menunjukkan bahwa bahan baku yang digunakan dalam proses produksi berstatus berlebih, hal tersebut menunjukkan ketersediaan bahan baku belum sepenuhnya dimanfaatkan. Melihat hasil tersebut, maka jika ketersediaan bahan baku ditambah tidak akan meningkatkan keuntungan, maka nilai dual price secara keseluruhan bernilai sama dengan nol. Berdasarkan dari hasil optimasi ini bahan baku mengalami kelebihan karena hanya digunakan pada keempat produk ini namun, ketersediaan bahan baku ini dapat digunakan untuk memproduksi produk produk yang lainnnya.

2. Penggunaan Tenaga Kerja Langsung

Faktor kedua adalah penggunaan jam tenaga kerja langsung dapat di lihat pada Tabel 5. 
Tabel 5. Hasil Optimasi Penggunaan Jam Tenaga Kerja

\begin{tabular}{lrrl}
\multicolumn{4}{c}{ Manusia } \\
Bagian & Slack/Surplus & Dual Prices & Status \\
\hline Persiapan & 259.047607 & 0.000000 & Berlebih \\
Mesin & 720.000000 & 0.000000 & Berlebih \\
Perakitan & 365.714294 & 0.000000 & Berlebih \\
Finishing & 0.000000 & 1616.988892 & Langka \\
\hline
\end{tabular}

Dimana hasil optimasi ketersediaan tenaga kerja mengalami kelebihan, hal tersebut menunjukkan ketersediaan jam tenaga kerja langsung belum sepenuhnya dimanfaatkan. Melihat hasil tersebut, maka jika ketersediaan tenaga kerja langsung ditambah tidak akan meningkatkan keuntungan, maka nilai dual price secara keseluruhan bernilai sama dengan nol. Berdasarkan hasil optimasi diatas tenaga kerja pada bagian finishing merupakan salah satu sumberdaya pembatas dalam proses produksi karena di bagian finishing ini mengalami kelangkaan sedangkan untuk tenaga kerja pada bagian lainnya masi mengalami kelebihan yang berarti masi bisa digunakan untuk memproduksi produk meubel lainnya.

3. Penggunaan Tenaga Kerja Mesin

Faktor ketiga adalah penggunaan jam tenaga kerja mesin dapat dilihat pada Tabel 6.

Tabel 6. Hasil Optimasi Penggunaan Jam Tenaga Kerja Mesin

\begin{tabular}{|c|c|c|c|c|}
\hline \multicolumn{5}{|c|}{ a. $\quad$ Bagian Persiapan } \\
\hline Mesin & $\begin{array}{r}\text { Slack/ } \\
\text { Surplus }\end{array}$ & $\begin{array}{r}\text { Dual } \\
\text { Prices }\end{array}$ & $\begin{array}{r}\text { Dual } \\
\text { Prices }\end{array}$ & Status \\
\hline Potong & 453.333344 & 0.000000 & 0.000000 & Berlebih \\
\hline Perata & 445.714294 & 0.000000 & 0.000000 & Berlebih \\
\hline Iris & 464.761902 & 0.000000 & 0.000000 & Berlebih \\
\hline Penebal & 460.952393 & 0.000000 & 0.000000 & Berlebih \\
\hline \multicolumn{5}{|c|}{ b. $\quad$ Bagian Mesin } \\
\hline Mesin & $\begin{array}{r}\text { Slack/ } \\
\text { Surplus }\end{array}$ & $\begin{array}{r}\text { Dual } \\
\text { Prices }\end{array}$ & Status & Mesin \\
\hline Potong & 457.142853 & 0.000000 & Berlebih & Potong \\
\hline Iris & 476.190491 & 0.000000 & Berlebih & Iris \\
\hline $\begin{array}{l}\text { Bor } \\
\text { vertikal }\end{array}$ & 449.523804 & 0.000000 & Berlebih & $\begin{array}{l}\text { Bor } \\
\text { vertikal }\end{array}$ \\
\hline Bor & 464.761902 & 0.000000 & Berlebih & Bor \\
\hline Horizontal & & & & Horizontal \\
\hline $\begin{array}{l}\text { Pembuat } \\
\text { lidah/pen }\end{array}$ & 476.190491 & 0.000000 & Berlebih & $\begin{array}{l}\text { Pembuat } \\
\text { lidah/pen }\end{array}$ \\
\hline Frais & 476.190491 & 0.000000 & Berlebih & Frais \\
\hline $\begin{array}{l}\text { Amplas } \\
\text { besar }\end{array}$ & 426.666656 & 0.000000 & Berlebih & $\begin{array}{l}\text { Amplas } \\
\text { besar }\end{array}$ \\
\hline $\begin{array}{l}\text { Amplas } \\
\text { kecil }\end{array}$ & 476.190491 & 0.000000 & Berlebih & $\begin{array}{l}\text { Amplas } \\
\text { kecil }\end{array}$ \\
\hline Bubut & 480.000000 & 0.000000 & Berlebih & Bubut \\
\hline \multicolumn{5}{|c|}{ c. $\quad$ Bagian Perakitan } \\
\hline Mesin & $\begin{array}{r}\text { Slack/ } \\
\text { Surplus } \\
\end{array}$ & $\begin{array}{r}\text { Dual } \\
\text { Prices }\end{array}$ & Status & Mesin \\
\hline Bor & 251.428574 & 0.000000 & Berlebih & Bor \\
\hline Routter & 205.714279 & 0.000000 & Berlebih & Routter \\
\hline \multicolumn{5}{|c|}{ d. $\quad$ Bagian Finishing } \\
\hline Mesin & $\begin{array}{r}\text { Slack/ } \\
\text { Surplus }\end{array}$ & $\begin{array}{r}\text { Dual } \\
\text { Prices }\end{array}$ & Status & Mesin \\
\hline $\begin{array}{l}\text { Kompress } \\
\text { or }\end{array}$ & 400.000000 & 0.000000 & Berlebih & Kompressor \\
\hline
\end{tabular}

\section{Analisis Sensitivitas}

Analisis sensitivitas dilakukan untuk mengetahui tingkat kepekaan model setelah diperoleh hasil optimasi ada, disamping berfungsi mengetahui hasil optimasi untuk diperlakukan pada kondisi dan situasi berbeda. Pada analisis sensivitas dapat melihat pengaruh dari selang kepekaan yang terdiri dari batas minimum dan maksimum.

1. Sensitivitas Koefisien Fungsi Tujuan

Analisis sensitivitas nilai koefesien fungsi tujuan merupakan perubahan harga terhadap koefesien fungsi tujuan yang tidak berpengaruh terhadap nilai optimal dari peubah. Hasil analisis sensitivitas koefisien fungsi tujuan memperlihatkan bahwa bangku gereja peka terhadap kenaikan harga sebesar 32,17\%. Atau RP. 327681,687500. Hasil analisis ini menjelaskan bahwa permintaan kotak persembahan, kursi HK dan sampiran bangku gereja peka terhadap penurunan harga.

2. Sensitivitas Sumberdaya

Analisis sensitivitas ruas kanan ini mencakup seluruh kendala yang terdiri dari kendala bahan baku, kendala jam tenaga kerja produksi langsung dan jam tenaga kerja mesin produksi.

Hasil analisis sensitivitas menunjukkan bahwa bahan baku yaitu engsel kuningan, kunci sis, kenop daun ukuran 3,5 dan kenop daun ukuran 3 pada BLPT peka terhadap penurunan namun tidak peka terhadap kenaikan. Untuk analisis sensitivitas pada tenaga kerja dibagi menjadi dua bagian yaitu tenaga kerja manusia dan tenaga keja mesin. Tenaga kerja manusia pada bagian finishing yang sensitif terhadap penurunan ketersediaan tenaga kerja manusia sebesar $61,53 \%$ atau turun sebesar 295.384613. Untuk tenaga kerja mesin mengalami kelebihan yang berarti peka terhadap penurunan namun tidak peka terhadap kenaikan.

\section{KESIMPULAN DAN SARAN}

\section{Kesimpulan}

a. Berdasarkan hasil penelitian diatas BLPT Kaaten telah beroperasi secara optimal yaitu memperoduksi 76 buah dalam jangka waktu 100 hari dengan keuntungan Rp.77.615.470. 
b. Sumberdaya pembatas dalam kegiatan produksi meubel BLPT Kaaten adalah Tenaga Kerja Manusia bagian Finishing sedangkan bahan baku dan tenaga kerja mesin dan tenaga kerja bagian persiapan, bagian mesin/ pengesahan, serta bagian perakitan.

c. Kepekaan sumberdaya peka terhadap penurunan ketersediaan engsel kuningan, kunci sisi, kenop daun ukuran 3,5 dan kenop daun ukuran 3.

\section{Saran}

a. Disarankan kepada BLPT Kaaten untuk memanfaatkan penggunaan sumberdaya yang ada dan memproduksi meubel rumah tangga untuk dipasarkan ke masyarakat umum.

b. BLPT Kaaten lebih memperhatikan tenaga kerja bagian finishing dengan cara menambahkan karyawan di bagian tersebut jika ingin menambah kapasitas produksi.

\section{DAFTAR PUSTAKA}

Aji S., Kusmaningrum \& M.F. Herni. 2014 . Optimisasi Keuntungan Menggunakan Linear Programming Di PT Pertamina Refinery Unit (RU) VI Balongan. Jurnal Online Institut Teknologi Nasional Jurusan Teknik Industri Itenas, Vol.01, No. 03.

Aminuddin. 2005. Prinsip-Prinsip Riset Operasi. Erlangga. Jakarta.

Assauri,S. 2004. Manajemen Produksi Dan Operasi. Fakultas Ekonomi Universitas Indonesia. Jakarta.

Baroto, T. 2002. Perencanaan Dan Pengendalian Produksi Ghalia Indonesia. Jakarta.

Denny Sindi Pratama. Optimalisasi Produksi Industri Sambal Menggunakan Pemrograman Linier (Optimalization Of Production Industrial Sauce Using Linear Programming).

Fachmi. 2014. Analisis Produksi Dan Pendapatan Industri Meubel Di Kota Makassar. Skripsi Pada Jurusan Ilmu Ekonomi, Fakultas Ekonomi Dan Bisnis, Universitas Hasanuddin. Makassar.

Heizer,J., \& R. Barry. 2005. Manajemen Operasi (Operations Management) Edisi Ketujuh. Salemba Empat. Jakarta.

Indrayanti. 2012. Menentukan Jumlah Produksi Batik Dengan Memaksimalkan Keuntungan Menggunakan Metode Linier Programming Pada Batik Hana. Jurnal Ilmiah ICTECH Vol.X No.1. 3 Juni 2016.

Lestari, S. 2009. Optimasi Produksi Adenium Dan Aglaonema Di PT. Istana Alam Dewi Tara Sawangan, Depok. Skripsi Pada Departemen Manajemen Agribisnis, Fakultas Pertanian, Institusi Pertanian Bogor. Bogor.
Luthfiyanti,R. 2003. Optimasi Produksi CPO (Crude Palm Oil) Di Pabrik Kelapa Sawitkertajaya Dengan Menggunakan Goal Programming. Skripsi Pada Jurusan Teknologi Industri Pertanian, Fakultas Teknologi Pertanian IPB. Bogor.

Mulyono, Sri. 1991. Operations Research. Lembaga Penerbit Fakultas Ekonomi Universitas Indonesia: Jakarta.

Nasikh.2009. Model Optimalisasi Faktor Produksi Usaha Industri Kecil Meubel Kayu Jati Di Pasuruan Jawa Timur. Jurnal Manajemen Dan Kewirausahaan, Vol. 11, NO.1.

Noer, B.A. 2010. Belajar Mudah Riset Operasional. Penerbit Andi. Yogyakarta.

Nurtaji, W., 2009. Optimalisasai Usahatani Sayuran Dataran Tinggi Sembalun, Lombok Timur. Agroteksos, Vol.19, No. 3.

Pardede, P.M., 2005. Manajemen Operasi Dan Produksi: Teori, Model, Dan Kebijakan Edisi Revisi. CV ANDI OFFSET. Yogyakarta.

Sartin. 2008. Analisis Perencanaan Tenaga Kerja Do Perushaan Redrying Tembakau Dengan Pendekatan Linear Programming. Jurnal Teknik Kimia, Vol.3, No.1. 14 Juni 2016.

Shanty Octaviani. 2012. Analisis Optimalisasi Produksi Roti Pada Marbella Bakery. Skripsi Pada Departemen Manajemen, Fakultas Ekonomi Manajemen, Institut Pertanian Bogor. Bogor.

Soekartawi. 1992. Linear Programming: Teori Dan Aplikasinya Khususnya Dalam Bidang Pertanian. Rajawali Press. Jakarta.

Sugiarto Christian. 2013 . Penerapan Liniear Programing Untuk Mengoptimalakan Jumlah Produksi Dalam Memperoleh Keuntungan Maksimal Pada CV CIPTA UNGGUL PRATAMA. Journal THE WINNERS, Vol 14, No.1, Hal 55-60

Taha, A. Hamdy. 1996 . Riset Operasi Suatu Pengantar Edisi Kelima Jilid 1. Jakarta : Binarupa Aksara.

Teguh. S \& E. Agustina. 2013. Analisis Optimalisasi Produksi Dengan Linear Programming Melalui Metode Simpleks. Binus Business Review Vol.4 No. 2, Hal 725-741.

Tiatra Supit, A.H.Jan.2015. Analisis Persediaan Bahan Baku Pada Industri Meubel Di Desa Leilem. Jurnal EMBA Vol.3, No.1. Manado.

Wirdasari. D., 2009. Metode Simpleks Dalam Rogram Linier. Jurnal SAINTIKOM Vol.6, No.1.

Yamit, Z. 2007. Manjemen Kuantitatif Untuk Bisnis (Operations Research) Edisi Pertama. Yogyakarta: BPFE-YOGYAKARTA.

Yuliawan,F.A.2009. Kajian Optimasi Untuk Meningkatkan Profitabilitas Pada PT.Pismatex, Pekalongan. Skripsi Pada Departemen Manajemen, Fakultas Ekonomi Dan Manajemen, Institusi Pertanian Bogor. Bogor. 